\title{
Designing Informal EAM Interventions - A Complementary Approach for Managing Enterprise Architecture Complexity
}

\author{
Robert Winter \\ Institute of Information Management, University of St.Gallen \\ robert.winter@unisg.ch
}

\begin{abstract}
Although Enterprise Architecture Management (EAM) is a mature discipline and widely adopted in practice, surveys indicate effectivity barriers that, at least partially, appear to be a consequence of local decision makers' non-compliance with enterprise-wide architectural guidelines. Several recent contributions aim at extending the portfolio of EAM interventions by applying informal control mechanisms. Although promising to extend EAM effectivity, informal interventions are apparently not much utilized in EAM practice. Based on the assumption that a comprehensive presentation of design knowledge for informal EAM interventions would support more widespread adoption, this paper integrates existing knowledge components to a coherent design approach. The proposal covers theoretical justification, conceptual foundations, a taxonomy of generic informal interventions, a catalogue of derived EAM intervention types, and a process to systematically instantiate and evaluate situation-specific informal interventions. Two Action Design Research projects in large companies are summarized as evaluative evidence for the potential that comprehensive informal intervention design has for improving EAM effectivity.
\end{abstract}

\section{Introduction}

Over the past decades, we have witnessed an enormous growth of investments in Information Systems (IS) in organizations. On the one hand, increasing investments in IS had a significant impact on most organizations' performance. On the other hand, these investments resulted in a significant complexity of the corporate IS architecture - i.e., the organization's fundamental IS components, their inter-relationships, and the principles governing their design and evolution [1]. The majority of the IS complexity increase is inevitably caused by growing business complexity and digitalization. An avoidable, often significant portion of that rise, however, can be attributed to the allocation of project ownership and IS design decision authority to local (business) units that focus on their specific ("local") objectives rather than on enterprise-wide goals [2]. To address this challenge and confine the IS complexity increase to a sustainable extent, scholars and practitioners have broadly propagated the concept of Enterprise Architecture Management (EAM) for systematically aligning locally governed IS investments with enterprise-wide objectives [3].

The EAM discipline has matured a lot over the last three decades. Its scope diversified from software architecture to application architecture and from process architecture to business architecture. Its focus widened from IS solutions over functional/business areas to enterprise-wide or even to cross-enterprise architecture. Its sphere of influence expanded from a single architectural layer (e.g., software and IT infrastructure) to the entire business-to-IT stack. Finally, its coverage extended from representing as-is or to-be states of various architectural entities to roadmaps or scenarios that cover complete, sometimes even multiple solution life cycles. Following EAM's raise in maturity, it has largely gained momentum so that organizations established various 'architect' roles and functions [4].

Notwithstanding these advances, the EAM discipline still struggles with some formational challenges. First, although many architects tried to position themselves as a linking-pin 'between' corporate management, business/project owners and IT, their backgrounds and competency profiles often kept them close to the corporate IT functions [5], limiting their credibility on the business side. Second, exercising EAM as a centralized mechanism for enterprise-wide IS coordination is often perceived to be the antagonist of innovation projects. From local business stakeholders' perspective (e.g., a particular project, product, or function owner), the promoted enterprise-wide coordination by EAM is often regarded to be a "restriction of design freedom" [6] and not supportive to their goals.

The perception of EAM and, consequently, its impact on keeping IS complexity at sustainable levels, may be linked to the form in which EAM intervenes in the organization [5]. In its traditional fashion, formal control mechanisms are implemented that aim at 
maintaining transparency, coherency, and ultimately flexibility of IS architecture. Such mechanisms include, but are not limited to developing, maintaining, and enforcing architecture principles, architecture compliance checks, to-be architectures, and committees or procedures for architectural coordination, to eventually influence decisions made in IS development projects [7].

After harvesting 'low hanging fruits', however, it becomes increasingly difficult for EAM to consistently create significant benefits. A much discussed MIT study shows that, at some point, EAM apparently reaches its peak productivity level [5]. Simultaneously, IS architecture complexity can be expected to remain high or even increasing. The observation of decreasing marginal coordination benefits appears not to be related to maturity deficits of EAM concepts or deployment, but rather to general acceptance problems of EAM interventions by local stakeholders [5]. Hence, increasing compliance of local decision-makers in innovation projects becomes a key priority for further developing enterprise-wide architectural coordination and, ultimately, keeping IS complexity at a sustainable level.

Informal coordination interventions have the potential to extend the portfolio of IS coordination mechanisms beyond incentives and sanctions $[8,9]$, thereby promising to at least partially overcome stakeholder resistance and improve EAM effectivity. While certain components and aspects of informal coordination have been already investigated and published, these components have not been integrated into a comprehensive design approach yet. We posit that the missing adoption in practice is at least partially caused by the fragmented nature of design knowledge. This paper therefore aims at integrating the pieces, answering the research question 'how can fragmented design knowledge about informal interventions be integrated to provide a comprehensive design support for EAM?'

\section{Methodology and Approach}

Ideally, comprehensive design knowledge should combine (i) justificatory descriptive knowledge, (ii) derived projectable design knowledge on multiple levels of (de)contextualization, and (iii) expository design instances for demonstration and evaluation purposes in a coherent form [10]. As our conceptual 'integration template', we adapt this design knowledge concept to EAM in Section 2. According to the multi-level knowledge structure, we first analyze the portfolio of coordination interventions through the lens of control theory and institutional theory as conceptual foundations (justificatory descriptive knowledge, Section 3). On that basis, we conceptualize suitable informal control interventions in Section 4 (abstract design knowledge). Contextualizing such abstract design knowledge is a multi-stage process. As a first important step, Section 5 presents the derivation of a company-specific portfolio of informal interventions. Section 6 then presents a method how specific informal EAM interventions (design instances) can be created on that basis. It should be noted that all presented design knowledge components have been elaborated and published before, but isolated and not as an integral component of comprehensive, coherent design knowledge. To demonstrate our proposal, we report results from developing concrete informal coordination interventions in a large company (Section 7) before concluding in Section 8.

As our research question is about how to solve a specific class of problems, our research design generally follows the Design Science Research approach [11]. Sections 3 and 4 summarize conceptual and theoretical foundations, Sections 5 and 6 present solution components (intervention design approach), and Section 7 reports demonstration and evaluation.

\section{Design Knowledge Model}

Based on their analysis of design knowledge evolution and accumulation, Avdiji and Winter [10] propose that design knowledge should coherently integrate components on different conceptual levels. In the following, we adapt their conceptual template to EAM interventions:

- Descriptive knowledge as justification: In the case of EAM, coordination theory provides justificatory predictive statements about which preconditions create which effects (cause-effect relations). Section 3 summarizes relevant findings.

- Abstract design knowledge as a basis for contextualization: It has been shown that certain types of informal coordination interventions are effective for reaching specific coordination goals (meansends relations). Section 4 presents a generic typology of 26 such interventions, albeit not yet contextualized for EAM.

- Contextualized design knowledge as a basis for instantiation: In the case of EAM, every organization contextualizes generic informal interventions according to their goals, size, context dynamics, and other factors they find relevant. In Section 5, we report how informal EAM interventions are derived, illustrated by the case of a large insurance company which derived 23 types of informal EAM interventions. Such means-end relations are still projectable, but already contextualized to a problem sub-class (EAM interventions). 
- Finally, expository design instances allow to evaluate to which extent implemented EAM coordination interventions actually lead to desired coordination effects (design feature-measurable effect relations). In Section 6, we report how such an implementation can be done by integrating method components from Action Design Research and Digital Nudging.

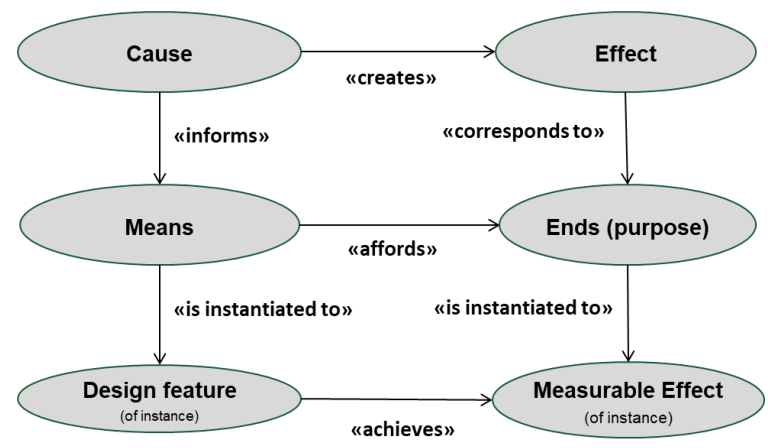

Figure 1. Design knowledge structure

Figure 1 illustrates the way the components of this study correspond to the conceptual structure of projectable design knowledge. The upper layer represents descriptive knowledge, the middle layer represents the core projectable design knowledge (which can consist of several sub-layers of increasing contextualization), and the lower layer represents expository design instances.

\section{Descriptive Foundation: Informal Coor- dination Mechanisms in EAM}

From a coordination theory perspective, EAM interventions implement different types of control mechanisms [12]. Table 1 summarizes an adapted compilation of Schilling's [7] analysis which modes and mechanisms of control are implemented by which exemplary EAM interventions.

As a foundation, EA frameworks and modeling methods are used to conceptualize and describe EA while measurement systems quantify the effects of EAM. Architecture principles, EA planning processes and EA governance structures are put in place to plan and control EA. On that basis, architectural norms and values need to become institutionalized across the organization in order to assure EAM impact $[4,5,13]$. While formal control mechanisms appear to work well to plan and control EA, appropriate control mechanisms for institutionalizing EAM are much less known. This becomes evident when looking at the many organizations that have a long track record of EAM, but have not yet succeeded in establishing an enterprise-wide perspective beyond the IT function [5].

Convincing local stakeholders that overall benefits on the enterprise-wide level justify individual sacrifices, remains a difficult undertaking. Illustrative examples of such challenge cannot only be found in enterprises (e.g., centralizing procurement processes), but are also common in public policy (e.g., imposing speed limits around schools, imposing smoking bans in public areas, transforming energy production and consumption).

Table 1. Formal and informal control mechanisms in EAM (adapted from [7])

\begin{tabular}{|c|c|c|c|}
\hline \multicolumn{2}{|c|}{ Mode of control } & Definition & $\begin{array}{l}\text { EAM exem- } \\
\text { plars }\end{array}$ \\
\hline \multirow[t]{3}{*}{$\begin{array}{l}\text { Formal } \\
\text { control }\end{array}$} & $\begin{array}{l}\text { Input } \\
\text { control }\end{array}$ & $\begin{array}{l}\text { Control through the allo- } \\
\text { cation of } \\
\text { - human resources } \\
\text { - financial resources } \\
\text { - material resources } \\
\text { - organizational arrange- } \\
\text { ments }\end{array}$ & $\begin{array}{l}\text { Situational } \\
\text { EAM [14] }\end{array}$ \\
\hline & $\begin{array}{l}\text { Behavior } \\
\text { control }\end{array}$ & $\begin{array}{l}\text { Control through the defini- } \\
\text { tion of } \\
\text { - processes to govern the } \\
\text { actions of individuals } \\
\text { - mechanisms to observe } \\
\text { the behavior of various } \\
\text { stakeholders } \\
\text { - rules in guiding actions } \\
\text { - reward systems for com- } \\
\text { pliance }\end{array}$ & $\begin{array}{l}\text { - EAM stand- } \\
\text { ards \& princi- } \\
\text { ples } \\
{[15,16]} \\
\text { - EAM frame- } \\
\text { works } \\
{[17,18]} \\
\text { - EAM Ma- } \\
\text { turity models } \\
{[19]}\end{array}$ \\
\hline & $\begin{array}{l}\text { Outcome } \\
\text { control }\end{array}$ & $\begin{array}{l}\text { Control through the defini- } \\
\text { tion of } \\
\text { - specifications of desired } \\
\text { outcomes } \\
\text { - processes to measure and } \\
\text { promote outcomes }\end{array}$ & $\begin{array}{l}\text { - EA model- } \\
\text { ing methods } \\
{[20,21]} \\
\text { - EA(M) out- } \\
\text { come } \\
\text { measures } \\
{[22,23]}\end{array}$ \\
\hline \multirow[t]{2}{*}{$\begin{array}{l}\text { Informal } \\
\text { control }\end{array}$} & $\begin{array}{l}\text { Self con- } \\
\text { trol }\end{array}$ & $\begin{array}{l}\text { Control through the defini- } \\
\text { tion of } \\
\text { - goals by individuals } \\
\text { - individual's voluntary } \\
\text { improvement/ } \\
\text { learning activities }\end{array}$ & $\begin{array}{l}\text { Team-specific } \\
\text { EA guide- } \\
\text { lines/ chal- } \\
\text { lenges [24] }\end{array}$ \\
\hline & $\begin{array}{l}\text { Clan } \\
\text { control }\end{array}$ & $\begin{array}{l}\text { Control through values } \\
\text { and norms } \\
\text { - shared norms, values, } \\
\text { and beliefs } \\
\text { - reflection activities }\end{array}$ & $\begin{array}{l}\text { - Architectural } \\
\text { thinking [25] } \\
\text { - Influence- } \\
\text { based ap- } \\
\text { proaches [26] }\end{array}$ \\
\hline
\end{tabular}

In order to move beyond the already reached productivity (and impact) plateau of EAM, it appears necessary to shift the focus from an enforcement-centric view (i.e., focusing on formal control mechanisms, e.g. by enhancing EAM governance) towards an influence-centric view (i.e., using informal control mechanisms). This implies also a shift of focus from the traditional EAM players (IT unit, architects, enterprise management) to "that other $90 \%$ of the enterprise" [5] that are not directly related to the IT function or 
enterprise-wide concerns. As these stakeholders (e.g., project, product, or function owners) cannot be sufficiently "controlled" by traditional EAM interventions with a reasonable effort, EAM needs to focus not only on enforcement, but also (or even more) on influencing. As a consequence, formal control as a central theme of EAM research needs to be complemented by informing, legitimating, and socializing [7].

For formal interventions, organizations have developed mature practices to measure compliant behavior (e.g., by systematic assessment of compliance with architectural guidelines in the context of sign-offs), to incentivize desired reactions (e.g., by approving compliant project proposals), and to sanction undesired reactions (e.g., by demanding proposal amendments). For the purposeful design of informal interventions, however, the foundations of compliance need to be investigated first. The model of Weiss et al. [26] explains individual reaction to EAM interventions and thus can serve as a starting point. According to their study, individual actors

1. Need to be convinced that their social status will be rising if they comply with EAM interventions;

2. Need to understand that they can be more efficient if they comply with EAM interventions;

3. Need to perceive EAM as something that is strategically important for the organization; and

4. Need to perceive EAM as transparent, business-oriented and trustworthy.

As a consequence, the general approach of extending the portfolio of EAM interventions requires actively involving local decision-makers and the social system of the organization, focus on communication and sensemaking, using lightweight tools without too much 'IT touch', and demonstrating local, tangible benefits of architectural coordination. The resulting ambition has been designated as "Architectural Thinking" [25].

\section{Design Foundation: Taxonomy of Po- tential Informal Control Interventions}

Based on a broad structured literature review, Kneubühler [27] classified coordination interventions according to the underlying psychological base mechanisms, their timing and whether the respective decisions are infrequent or repetitive. If also the level of analysis is considered, the resulting taxonomy differentiates 23 types of informal interventions, three types of formal interventions and three mixed types. They are listed in Table 2.

The resulting range of 26 types of informal interventions constitutes a 'menu' of general (informal) solution components to general coordination problems in organizations. From that generic means-ends 'menu', a specific set of informal intervention candidates can be derived by choosing the acceptable or desired base mechanism, the type of decision and the relevant level of application (individual, workgroup, community, or enterprise) as filters. Yet the resulting set of candidates is neither specifically tailored to EAM nor to the specific context of an organization.

Table 2. Types of interventions (adapted from [27])

\begin{tabular}{|c|c|c|c|c|c|}
\hline Intervention type & Level & $\begin{array}{c}\text { Base } \\
\text { mecha- } \\
\text { nism }\end{array}$ & Timing & $\begin{array}{c}\text { Deci- } \\
\text { sion } \\
\text { type } \\
\end{array}$ & $\begin{array}{l}\text { Type of } \\
\text { control }\end{array}$ \\
\hline Social norms & I & $\mathrm{S}$ & -0 & $1 \mathrm{n}$ & I \\
\hline $\begin{array}{l}\text { Loss aversion / } \\
\text { negative framing }\end{array}$ & I & $\mathrm{F}$ & + & $1 \mathrm{n}$ & $\mathrm{F}$ \\
\hline Positive framing & I & $\mathrm{R}$ & - & $1 \mathrm{n}$ & I \\
\hline Setting standards & $\mathrm{IOS}$ & $\mathrm{C}$ & 0 & 1 & F I \\
\hline Priming & $\mathrm{I}$ & $\mathrm{C}$ & - & $1 \mathrm{n}$ & $\mathrm{I}$ \\
\hline Anchoring & $\mathrm{I}$ & $\mathrm{C}$ & -0 & 1 & $\mathrm{I}$ \\
\hline $\begin{array}{l}\text { Hyperbolic dis- } \\
\text { counting }\end{array}$ & I & $\mathrm{C}$ & -0 & 1 & I \\
\hline $\begin{array}{l}\text { Preventing hyper- } \\
\text { bolic discounting }\end{array}$ & $\mathrm{I}$ & $\mathrm{A}$ & -0 & 1 & I \\
\hline Simplification & I T S & $\mathrm{A}$ & 0 & 1 & I \\
\hline Salience & I T & $\mathrm{A}$ & -0 & $1 \mathrm{n}$ & $\mathrm{I}$ \\
\hline $\begin{array}{l}\text { Transparency and } \\
\text { disclosure }\end{array}$ & I T O S & $\mathrm{A}$ & -0 & $1 \mathrm{n}$ & F I \\
\hline Feedback & $\mathrm{I} \mathrm{T}$ & $\mathrm{A}$ & - & $\mathrm{n}$ & F I \\
\hline Binding & $\mathrm{I}$ & F R & - & $\mathrm{n}$ & $\mathrm{I}$ \\
\hline $\begin{array}{l}\text { Persuasive commu- } \\
\text { nication }\end{array}$ & I & $\mathrm{C}$ & - & $1 \mathrm{n}$ & I \\
\hline Sensitivity training & I T G O & $\mathrm{A}$ & - & $1 \mathrm{n}$ & I \\
\hline $\begin{array}{l}\text { Cross-functional } \\
\text { training }\end{array}$ & T GO & $?$ & - & $1 \mathrm{n}$ & I \\
\hline Networking & $\mathrm{GO}$ & $\mathrm{S}$ & - & $1 \mathrm{n}$ & $\mathrm{I}$ \\
\hline $\begin{array}{l}\text { Stakeholder In- } \\
\text { volvement }\end{array}$ & T O & $\mathrm{S}$ & 0 & $1 \mathrm{n}$ & I \\
\hline $\begin{array}{l}\text { Buildup of social } \\
\text { capital }\end{array}$ & I T & $\mathrm{S}$ & - & $1 \mathrm{n}$ & I \\
\hline Moral contracts & I T & $\mathrm{F}$ & - & $1 \mathrm{n}$ & $\mathrm{I}$ \\
\hline Peer review & T G & $\mathrm{F}$ & + & $1 \mathrm{n}$ & $\mathrm{F}$ \\
\hline Peer pressure & I T G & S F & $-0+$ & $1 \mathrm{n}$ & $\mathrm{I}$ \\
\hline $\begin{array}{l}\text { Corporate / group } \\
\text { culture }\end{array}$ & I T G O & S F & $-0+$ & $1 \mathrm{n}$ & I \\
\hline Norms and values & I T G O & S F & $-0+$ & $1 \mathrm{n}$ & I \\
\hline $\begin{array}{l}\text { Defining individual } \\
\text { norms }\end{array}$ & I & F R & - & $1 \mathrm{n}$ & I \\
\hline $\begin{array}{l}\text { Creating obliga- } \\
\text { tions }\end{array}$ & $\mathrm{I}$ & $?$ & $-0+$ & $1 \mathrm{n}$ & $\mathrm{I}$ \\
\hline Checklists & I T & $\mathrm{A}$ & 0 & $1 \mathrm{n}$ & $\mathrm{F}$ \\
\hline $\begin{array}{l}\text { Psychological own- } \\
\text { ership }\end{array}$ & I & $?$ & $-0+$ & $1 \mathrm{n}$ & I \\
\hline $\begin{array}{l}\text { Psychological bind- } \\
\text { ing }\end{array}$ & I T & $?$ & $-0+$ & $1 \mathrm{n}$ & I \\
\hline
\end{tabular}

Legend:

Level: I=individual; T=team/workgroup; $\mathrm{G}=$ guild/community; $\mathrm{O}=$ organization; $\mathrm{S}=$ society

Base mechanism: $\mathrm{S}=$ status/image; $\mathrm{F}=$ fear/sanction; $\mathrm{R}=$ reward/incentive; $\mathrm{C}=$ carelessness; $\mathrm{A}=$ attentiveness

Timing: - =before; $0=$ during; $+=$ after decision-making

Type of decision: $1=$ once-only; $n=$ repetitive

Type of control: $F=$ formal; $I=$ informal 
The next contextualization steps are therefore (i) to 'translate' the general coordination goals into the context of EAM and (ii) to consider company-specific context factors such as, to name a few, its organizational setup, its EAM maturity, context dynamics, and / or specific coordination needs and practices. In the following section, we demonstrate how such a contextualization can be achieved.

\section{Deriving a Company-specific Portfolio of Informal EAM Interventions}

Any instantiation of generic design guidance requires a sufficiently detailed analysis of the respective context. In his case study at a large insurance company, Erni [28] interviewed major stakeholders of enterprise-wide coordination (such as senior management, strategic planning \& controlling, project portfolio management, IT project lead, business analyst, product owner, innovation manager) to collect a consolidated characterization of the context. As most important context characteristics, he identified the company's approach to IT/business alignment, its EAM maturity, current impact of EAM outcomes impact, current coordination needs and incentives, current practice of making decisions with effect on EA, the magnitude of complexity costs, and the level of the resulting corporate performance impact.

Based on this context analysis, he combined generic interventions from the catalogue presented in the preceding section to derive 23 informal intervention candidates. Based on a qualitative analysis, he organized the candidates in seven clusters: [28]

1. "Classical" EAM interventions

2. Decision support

3. Proactive information provision

4. Establishment of new communication channels

5. Enabling of collaboration and engagement

6. Adaptation of the EAM operating model

7. Involving the company's social system

The intervention candidates are based on the already mentioned study of Weiss et al. [26] that explains the reaction of non-architects to architectural coordination interventions. Erni specifies them not only regarding means (how they work), desired outcomes and addressees, but also with regard to whether their contribution would increase awareness, understanding, use, legitimacy, effectivity, organizational grounding, or trust of architectural coordination. While understanding, awareness and use result from general IS success models, the latter four factors had been identified by Weiss et al. to explain a large extent of EAM impact.

Table 3. Contextualized catalogue of informal interventions (adapted from [28])

\begin{tabular}{|c|c|c|c|}
\hline Cluster & Intervention & \begin{tabular}{|c|} 
Expected \\
useful- \\
ness
\end{tabular} & \begin{tabular}{|c|}
$\begin{array}{c}\text { Expected } \\
\text { practica- } \\
\text { bility }\end{array}$ \\
\end{tabular} \\
\hline \multirow{3}{*}{$\begin{array}{l}\text { "Classical" EAM } \\
\text { interventions }\end{array}$} & Incorporate EAM function early into business/project design decisions & 4 & 2.5 \\
\hline & Publish a catalogue of EAM services and analyses & 3.5 & 4.5 \\
\hline & Provide (architectural) checklists for certain types of decisions in projects & 3 & 3.5 \\
\hline \multirow[t]{2}{*}{ Decision support } & Provide individualized support for innovation projects & 3.5 & 2 \\
\hline & Strategic dialogue with senior management and steering committees of important innovation programs & 4 & 2.5 \\
\hline \multirow{3}{*}{$\begin{array}{l}\text { Proactive infor- } \\
\text { mation provision }\end{array}$} & Publish «success stories» of enterprise-wide coordination & 3.5 & 4 \\
\hline & Publish architecture roadmaps & 4 & 3 \\
\hline & Publish transparent calculations of IT and complexity costs & 3.5 & 3 \\
\hline \multirow{4}{*}{$\begin{array}{l}\text { Establishment of } \\
\text { new communica- } \\
\text { tion channels }\end{array}$} & Offer individualized, focused briefings for senior management & 2.5 & 4 \\
\hline & $\begin{array}{l}\text { Inform top management regularly about architectural issues (so that it becomes part of their middle } \\
\text { management briefings) }\end{array}$ & 2 & 3.5 \\
\hline & Conduct public «architecture talks» with internal and external speakers & 3 & 3 \\
\hline & Conduct trainings for specific architecture-relevant topics (e.g., complexity vs. agility) & 3.5 & 3 \\
\hline \multirow{5}{*}{$\begin{array}{l}\text { Enabling of col- } \\
\text { laboration and en- } \\
\text { gagement }\end{array}$} & Recruit and coach «coordination ambassadors» in business units or important projects & 2.5 & 2.5 \\
\hline & Establish an architecture board with all important management stakeholders (and selected specialists) & 3 & 2.5 \\
\hline & $\begin{array}{l}\text { Involve business stakeholders in architectural decisions (and also publish violations of architectural } \\
\text { principles/roadmaps) }\end{array}$ & 4 & 3 \\
\hline & Invite business/project representatives to develop architectural principles/roadmaps & 3.5 & 2 \\
\hline & Conduct architecture reviews and retrospectives for projects (where it matters) & 3.5 & 3.5 \\
\hline \multirow{3}{*}{$\begin{array}{l}\text { Adaptation of the } \\
\text { EAM operating } \\
\text { model }\end{array}$} & Lobby for consideration of architectural coordination objectives in enterprise-level objectives & 4.5 & 2.5 \\
\hline & Support major investment decisions by providing architecture-related decision support & 3.5 & 1.5 \\
\hline & Establish an product/service-centric (rather than a project-centric) EAM organization & 4 & 1.5 \\
\hline \multirow{3}{*}{$\begin{array}{l}\text { Involving the } \\
\text { company's social } \\
\text { system }\end{array}$} & $\begin{array}{l}\text { Create an enterprise-level assessment instrument (e.g., a label) for important decisions in innovation } \\
\text { projects and publish it }\end{array}$ & 3 & 3 \\
\hline & Facilitate peer reviews (architectural reviews of decisions by business peers rather than by EAM team) & 3 & 3 \\
\hline & $\begin{array}{l}\text { Create «architecture awards» to honor desirable behavior (compliant, sustainable innovations) of busi- } \\
\text { ness units or projects }\end{array}$ & 1.5 & 3 \\
\hline
\end{tabular}


Although the concrete context certainly varies from organization to organization, the approach to contextualize the pre-selected 'menu' of coordination interventions for EAM and for a company context, appear to be projectable to many organizations. While we now have informal EAM candidates rather than generic coordination interventions, we still have to identify which candidates are worth to be piloted, tested and eventually implemented.

In order to select and prioritize the 23 informal EAM intervention candidates for piloting, Erni conducted interviews with senior managers to determine their expected usefulness and expected practicability. Table 3 summarizes the results. For both constructs, 5 is the maximal and 1 is the minimal value.

While informal interventions directed at adapting the EAM operations model or decision support were assessed to be most useful, involving the company's social system was not regarded as very useful. Regarding practicability, it was not surprising that traditional, known interventions scored highest, along with information provision and new communication channels. The adaptation of EAM's operating model and decision support, although seen as most useful, were considered also to be most challenging with regard to their practicability.

Although we described so far how desirable informal EAM interventions with certain characteristics can be successively identified based on generic design guidance (decontextualized 'menu' and contextualized 'candidate list'), we still operate at an abstract 'intervention type' level. In order to concretely implement such interventions in practice, additional considerations are needed that are presented in the following section.

\section{Implementing Situated Informal EAM Interventions}

Once desired intervention types have been identified, the specification of concrete informal EAM interventions can apply not only (i) general guidelines for intervention design in organizations, but as well (ii) specific guidance for influencing individual behavior without coercion and, even more specific, (iii) specific guidance for adoption-friendly informal EAM interventions:

i. Since intervention instantiations are highly context-dependent and can only gain acceptance (and thus be used and create value) by the addressed decision-makers if they are sufficiently involved in the design process, we follow the Action Design Research (ADR) approach [29] as a general design method for intervention design in organizations. Thus, we co-produce the design together with practitioners, using an iterative approach to accompany and bring about the emergence of the artefact(s).

ii. For guiding individual level behavior without use of coercion or regulation, nudging has been widely studied since Thaler and Sunstein's [30] seminal book. The underlying psychological effects therefore provide a foundational toolbox for constructing contextualized digital nudges [31].

iii. As even more specific guidance for specifying informal interventions in an EAM context, we apply Weiss et al.'s guidelines for adoption-friendly EAM interventions [26].

The procedure we use is both informed by the four stages of ADR (problem formulation, building/intervention/evaluation, reflection/learning, and formalization of learning [29]) and the four-stage digital nudge design method by Mirsch et al. [31]. Cahenzli [32] consolidated these two methods into six phases:

Phase 1-Understanding the general problem: As part of the problem formulation of the ADR method and the steps related to understanding the context of the intervention, the first step is to understand the underlying problem.

Phase 2 - Formulation of problems from the stakeholders' perspective: Next, the problem is being described in statements from the perspective of the addressees whose behavior should be guided. Thereby, psychological effects are to be identified. This step is still part of the problem formulation in the ADR method, whereas it is overlapping phase 1 and 2 of the digital nudge design method.

Phase 3 - Forward, Backward, and Sidestep Mapping: The researchers and a work group consisting of relevant stakeholders within the case organization map the problem to existing and proven nudges and vice-versa (forward and backward mapping). This is part of the stage 2 of the ADR method and phase 2 of the digital nudge method. To increase the creativity of both researchers and practitioners, we additionally map the problem to psychological effects (and from there, to nudges that have been used to overcome said effects) as well as a suite of effects to possible nudges that may be leveraged to overcome existing psychological effects (sidestep mapping).

Phase 4 - Formulation and implementation of a solution: Once phase 3 is completed, the suite of nudge ideas is used as the baseline for the creation of an intervention that addresses not only a problem instance, but the entire problem class. This step is the most complicated as the solution is not only a nudge, but an abstracted construction that addresses not the individual problem aspects (e.g. identified inhibiting effects), but the institutionalization process as a whole. 
Therefore, the design guidance of Weiss et al. becomes important in this phase. As a consequence of their explanatory model of stakeholder reaction to EAM interventions, Weiss et al. suggest the following design principles [26]:

1. The interventions need to create transparent conditions about who is compliant with EAM guidelines and who is not - so that compliance can be associated with personal social status in the organization;

2. The interventions need to clearly demonstrate their positive value contribution also to 'local' objectives or goals - as well as the damage of ignoring or compromising the intervention to both local and global objectives / goals;

3. The interventions need to position EAM leaders on senior 'decider' levels in the organizational hierarchy - rather than 'ivory tower' experts or 'architectural police';

4. The interventions need to ensure that architects and architectural artifacts are not only understandable for business stakeholders, but also are able to credibly demonstrate their value contribution. For instance, the use of coherency-oriented, high complexity models should be avoided. Instead, when interacting with local business stakeholders, the focus of architects should be on lightweight artifacts, local business concerns and tangible benefits.

Only if as many as possible of these principles are followed, respective informal coordination interventions promise to effectively influence autonomous, local decision-makers on the business side towards increasing their acceptance of EAM guidelines and, ultimately, lead to an institutionalization of Architectural Thinking [33].

Once a version of an intervention is created, even if it is still at an early stage, it is being tested and learnings from this cycle are being fed back into the design process, until a large-scale implementation of the solution can be implemented. This testing and learning can be understood as stage 3 in the ADR method.

Phase 5-Evaluation: As opposed to the iterative testing and thus formative evaluation in phase 4 , this phase represents a summative evaluation of the design endeavor. At this point, the goals from phase 1 are used as a baseline to evaluate the artefact.

Phase 6 - Formalization of Learnings: As our intention is not primarily to solve the situated problem in a specific organization, the last phase tries to generalize the findings, addressing the general (decontextualized) problem. Therewith the ADR project may conceptually contribute to a better understanding of the problem, the solution, and finally, the creation of general design principles [29].

\section{Demonstration and Evaluation}

We conducted two actual development projects that applied the presented approach to implement (and partially deploy) informal coordination intervention instantiations in two different large organizations - aiming to institutionalize enterprise-wide coordination in a context where local decision-makers have very high autonomy.

In both cases, we used control and institutional theory to identify projectable design knowledge (here: menu of generic interventions) that was successively adapted to the relevant context of the case organizations (here: derivation of intervention candidates). In the following, we focus on how the intervention candidates were selected and implemented in one of these projects (for further details, see [34]). Where applicable, insights from the second project are complementing the summary.

Phase 1: The case company is a very large, multinational organization in the engineering industry. Traditionally, the case organization has been operating in a diversification mode and, hence, had a relatively low level of business process and information system integration and standardization. In 2016, the organization started to intensify its EAM activities. As an initial step, senior management appointed an EAM team with enterprise-wide scope and objectives. These objectives included measures to increase business processes and user productivity, to enable end-to-end processes and reporting, to reduce IS operating costs, and to enhance security and compliance.

To achieve these objectives, the EAM team implemented a considerable number of formal control mechanisms: The case organization defined architecture principles and plans for a target architecture, and established a formalized approval process for all changes that affect the enterprise architecture. Furthermore, the team trained more than 430 employees (mostly project managers and business process owners) on EAM topics.

With regard to the four architecture maturity stages outlined by Ross et al. [3], the case organization is close to reach stage 3 , where "companies move from a local view of data and applications to an enterprise view" [3, p. 76] and where "standardizing shared data and core business processes involves taking control over business process design from local business unit leaders" [3, p. 77]. On this maturity level, the core governance issue is to find the means to align project priorities (i.e., local perspectives) with EAM objectives (i.e., enterprise-wide perspective).

Phase 2: Despite having both implemented a wide range of architectural governance processes (with formal control mechanisms) and trained a considerable 
number of employees on EAM, the EAM team did not fully achieve its objectives. More precisely, the EAM team was confronted with the fact that a larger and relevant group of employees were still reluctant to adopt enterprise-wide concerns when taking design decisions affecting the enterprise architecture. According to control theory, informal control was missing, as the shared norms and values did not yet emphasize the value of an enterprise-wide perspective sufficiently.

This reluctance was, for instance, manifested in project owners who still had a clear local (product, process, project) perspective, and did not sufficiently consider the side effects, or the use of synergies. Also, the costs created for later integration, operation, and decommissioning were not sufficiently taken into consideration when making design choices. As a result, the case organization was confronted with the negative consequences of operating a complex EA, such as high operating costs $(75 \%+$ of all IS costs), lacking global visibility of applications, and, as a consequence, redundancies (among the 5,000 applications), heterogeneity in technology infrastructure, and difficulties in reflecting business processes end-to-end in the IS landscape.

The observation of the EAM team is thereby congruent with the perception of other members of the organization. As an internal survey in the case company has shown, only approximately half of the participants $(52 \%)$ were familiar with architectural guidelines and the organization's target architecture. At the same time, only $15 \%$ of the participants believed that the IT application landscape met the requirements defined by the EAM team. As a consequence, the aim of the intervention design is to influence the decision-making process of local entities, so that these opt for design alternatives that are in line with enterprise-wide concerns.

Phase 3: As the company had already deployed many formal coordinative EAM interventions with unsatisfactory effects, the idea was to try a non-mainstream alternative: a pioneering informal intervention that involves the company's social system. Among the social interventions, the mixed company-researcher workgroup decided to create an enterprise-level assessment instrument for important decisions in innovation projects - and make results available throughout the company. Due to the existing experience with labels in other domains of institutionalization, it was decided to co-create and roll out an "Enterprise Architecture Label" (EAL). The EAL shall provide information on the contribution of local entities to the overall state of the enterprise architecture. It should then nudge local entities to consider enterprise-wide concerns when making their local, IS-related design choices.

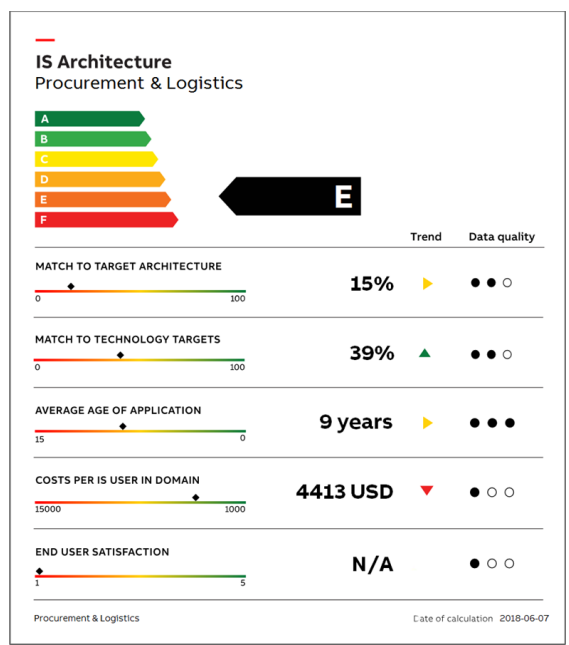

Figure 2. Enterprise architecture label [34]

The EAL was designed in three iterations. The first iteration encompassed all design activities with regard to the measurement system, i.e., the collection of measurement items to assess the degree to which local entities follow an enterprise-wide perspective. The second one focused on the aggregation process, i.e., the procedure to transform the results of the individual measurement items into an overall label rating. The third iteration was dedicated to the presentation, i.e., the actual design of the label. In all iterations, it was important to incorporate as many company architects, senior IT managers and business managers as possible to ensure that the EAL's message was understood, its data was credible and it could be expected that its company-public presentation (intranet) would have the aspired compliance effect. This phase's result, the EAL, is illustrated in Figure 2.

Phase 4: As the objective of ADR is to create (projectable) design knowledge [35] rather than just contextualized problem solutions, firstly several design revisions were done in the workgroup for the country unit were the label was intended to be rolled out, and secondly an additional, second country unit with slightly different contextual factors was chosen to triangulate not only EAL's usefulness evaluation, but also to contribute to the projectability of the design at least within the case organization.

In a separate project with a very large international bank (for details see [32]), an analysis of their coordination problems and intervention requirements also pointed towards a label-type informal intervention. A "data quality improvement label" was chosen in order to use the company's social system to create effects that were not achievable with formal coordination interventions before. Experience from the EAL was used as an input, and consolidated insights from both projects allowed to derive generalized insights. 
Phase 5: As opposed to the iterative testing and thus formative evaluations in phase 4 , this phase represents a summative evaluation of the design endeavor. At this point, the requirements from phase 1 were used as a baseline to evaluate the artefact [31]. Evaluative evidence was collected

- from users by asking whether they understood the label's message, found the presented information credible and believed it would influence their decision-making and

- from IT management by analyzing whether autonomous decisions in fact complied better with enterprise-wide objectives after the roll-out of the intervention.

While the former results were encouraging, the evaluation of effects was made difficult by the fact that, in the engineering company, a significant portion of their business (and supporting IT applications) were carved out during the observation period and, in the bank, the pandemic and internal strategic decisions caused the new interventions to be rolled out with delay and as part of a larger system update.

Phase 6: The conceptual foundations of control theory, institutionalization theory, informal intervention typology, candidate portfolio derivation, ADR, digital nudge method and pilots in several business units (and even different companies) provided a good foundation for learnings that go beyond situated design experiences. Several conference papers allowed to present and discuss nascent design principles that are intended to ultimately lead to a design theory for informal coordination interventions.

\section{Discussion and Conclusions}

This paper aimed aims at integrating the pieces, answering the research question 'how can fragmented design knowledge about informal interventions be integrated to provide a comprehensive design support for EAM?' We have presented a coherent integration of design knowledge for informal EAM interventions, comprised of (i) justificatory (descriptive) knowledge about interventions, effects and underlying mechanisms, (ii) projectable design knowledge about both fundamental intervention types, their contextualization, their selection and their implementation, and (iii) contextualized insights from two implementation projects. While there are many possible ways to (a) design and implement informal control mechanisms and (b) contextualize generic intervention design knowledge, we focused on the very promising and broadly adopted concept of (digital) nudging and on actual experience from two large companies. Figure 3 'fills' the concepts illustrated by Figure 1 with the concrete design knowledge we integrated.

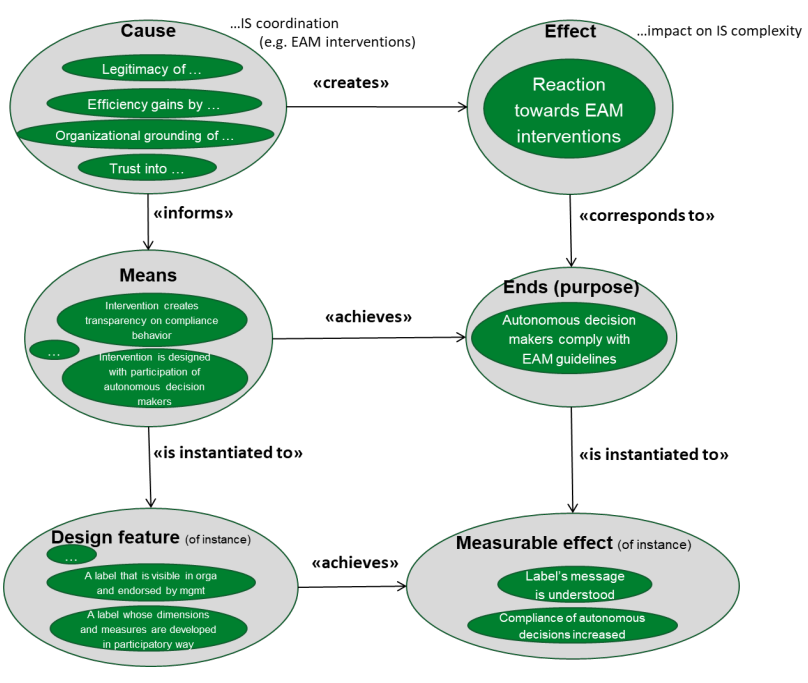
Figure 3. Mapping study results to design
knowledge structure

Although our study aimed at a high level of projectability, subsequent studies and case reviews may very well extend the design foundations and allow to identify additional relevant characteristics, additional intervention types and more elaborate design methods. Being designed artifacts, taxonomies and methods are intended to be useful for a specific purpose - so that different objectives and contexts may require changes and / or extensions.

IT managers and enterprise architects may appreciate this research as a valuable source of inspiration when extending their portfolio of control mechanisms. They may either be inspired by or adapt the contextfree intervention typology, adapt the EAM intervention catalogue to their company context, or even the presented instantiation to their particular needs - or they may be encouraged to identify and try out new, innovative informal control mechanisms. Ultimately, we hope to contribute to an avenue that hopefully allows EAM to overcome empirically observed productivity barriers and continues to constitute an effective approach for enterprise-wide coordination also in times of increased decentralization of IS design decisions.

\section{References}

[1] Ieee. (2000) IEEE Recommended Practice for Architectural Description of Software Intensive Systems (IEEE Std 1471-2000). New York, NY.

[2] M. Brosius, S. Aier, M. K. Haki, and R. Winter, "The institutional logic of harmonization: local versus global perspectives," in Enterprise Engineering Working Conference, 2018: Springer, pp. 3-17.

[3] J. W. Ross, P. Weill, and D. C. Robertson, Enterprise Architecture as Strategy. Creating a Foundation for 
Business Execution, Harvard Business School Press, Boston, MA, 2006.

[4] R. Winter, "Establishing 'Architectural Thinking' in Organizations", in The Practice of Enterprise Modeling: 9th IFIP WG 8.1. Working Conference, PoEM 2016, Springer, Cham, 2016, pp. 3-8.

[5] J. W. Ross and A. Quaadgras, "Enterprise Architecture Is Not Just for Architects," Center for Information Systems Research Massachusetts Institute of Technology, Cambridge, MA, 2012.

[6] J. L. G. Dietz, Architecture. Building strategy into design, Academic Service, The Hague, 2008.

[7] R. D. Schilling, "Enterprise Architecture Complexity: Implications for the Portfolio of Control Mechanisms," $\mathrm{PhD}$ Dissertation, University of St. Gallen, 2020.

[8] A. Tiwana, "Systems Development Ambidexterity: Explaining the Complementary and Substitutive Roles of Formal and Informal Controls", Journal of Management Information Systems, vol. 27, no. 2, 2010, pp. 87-126.

[9] A. Susilo, J. Heales, and F. Rohde, "Project Management Effectiveness: The Choice-Formal or Informal Controls", Australasian Journal of Information Systems, vol. 15, no. 1, 2007, pp. 153-167.

[10] H. Avdiji and R. Winter, "Knowledge Gaps in Design Science Research," presented at the Proceedings of the 40th International Conference on Information Systems, Munich, Germany, 2019.

[11] K. Peffers, T. Tuunanen, M. Rothenberger, and S. Chatterjee, "A Design Science Research Methodology for Information Systems Research", Journal of Management Information Systems, vol. 24, no. 3, 2007, pp. $45-77$.

[12] W. A. Cram, M. K. Brohman, and B. R. Gallupe, "Addressing the Control Challenges of the Enterprise Architecture Process", Journal of Information Systems, vol. 29, no. 2, 2015, pp. 161-182.

[13] S. Aier, N. Labusch, and P. Pähler, "Implementing Architectural Thinking: A Case Study at Commerzbank AG," in Proceedings of the CAiSE 2015 Workshops.

[14] S. Aier, B. Gleichauf, and R. Winter, "Understanding Enterprise Architecture Management Design - An Empirical Analysis," in Proceedings of the 10th International Conference on Wirtschaftsinformatik (WI 2011).

[15] W. F. Boh and D. Yellin, "Using Enterprise Architecture Standards in Managing Information Technology", Journal of Management Information Systems, vol. 23, no. 3, 2006, pp. 163-207.

[16] G. L. Richardson, B. M. Jackson, and G. W. Dickson, "A Principles-Based Enterprise Architecture: Lessons from Texaco and Star Enterprise", MIS Quarterly, vol. 14, no. 4, 1990, pp. 385-403.

[17] The Open Group, The Open Group Architecture Framework (TOGAF) Version 9.2, 2018.

[18] J. A. Zachman, "A Framework for Information Systems Architecture", IBM Systems Journal, vol. 26, no. 3, 1987, pp. 276-292.

[19] J. W. Ross. (2006) Enterprise Architecture: Driving Business Benefits from IT. MIT Sloan Research Paper.
[20] R. Winter and R. Fischer, "Essential Layers, Artifacts, and Dependencies of Enterprise Architecture", Journal of Enterprise Architecture, vol. 3, no. 2, 2007, pp. 7-18.

[21] M. Lankhorst, Enterprise Architecture at Work: Modelling, Communication and Analysis, 2 ed., Springer, Berlin, Heidelberg, 2009.

[22] C. Schmidt and P. Buxmann, "Outcomes and Success Factors of Enterprise IT Architecture Management: Empirical Insight from the International Financial Services Industry", European Journal of Information Systems, vol. 20, no. 2, 2011, pp. 168-185.

[23] M. Lange, J. Mendling, and J. Recker, "An Empirical Analysis of the Factors and Measures of Enterprise Architecture Management Success", European Journal of Information Systems, vol. 25, no. 5, 2016, pp. 411431.

[24] Ö. Uludağ, S. Nägele, and M. Hauder, "Establishing Architecture Guidelines in Large-Scale Agile Development Through Institutional Pressures," in Proceedings of the 25th Americas Conference on Information Systems (AMCIS 2019).

[25] R. Winter, "Architectural Thinking", Business \& Information Systems Engineering, vol. 6, no. 6, 2014, pp. 361-364.

[26] S. Weiss, S. Aier, and R. Winter, "Institutionalization and the Effectiveness of Enterprise Architecture Management," in Proceedings of the 34th International Conference on Information Systems (ICIS 2013).

[27] L. Kneubühler, "Interventionen für einflussbasiertes Unternehmensarchitekturmanagement," Master Thesis, Universität St.Gallen, 2019.

[28] D. Erni, "Entwicklung von Massnahmen zur Förderung von Architectural Thinking in der CSS Versicherung," Diplomarbeit, Universität St. Gallen, 2020.

[29] M. K. Sein, O. Henfridsson, S. Purao, M. Rossi, and R. Lindgren, "Action Design Research", MIS Quarterly, vol. 35 , no. 1,2011 , pp. 37-56.

[30] R. H. Thaler and C. R. Sunstein, Nudge. Improving Decisions About Health, Wealth and Happiness, Penguin, London, UK, 2008.

[31] T. Mirsch, C. Lehrer, and R. Jung, "Making Digital Nudging Applicable: The Digital Nudge Design Method," in Proceedings of the 39th International Conference on Information Systems (ICIS 2018).

[32] M. Cahenzli. Guiding the Institutionalization of Behaviour: Designing a Nudging-inspired Solution. Working Paper, University of St. Gallen, 2020.

[33] J. W. Meyer and B. Rowan, "Institutionalized Organizations: Formal Structure as Myth and Ceremony", American Journal of Sociology, vol. 83, no. 2, 1977, pp. 340-363.

[34] R. D. Schilling, S. Aier, and R. Winter, "Designing an Artifact for Informal Control in Enterprise Architecture Management," in Proceedings of the 40th International Conference on Information Systems (ICIS 2019).

[35] J. vom Brocke, R. Winter, A. R. Hevner, and A. Maedche, "Accumulation and Evolution of Design Knowledge in Design Science Research - A Journey Through Time and Space", Journal of The Association for Information Systems, vol. 21, no. 3, 2020, pp. 520544. 